\title{
Spindle Assembly Interaction
}

National Cancer Institute

\section{Source}

National Cancer Institute. Spindle Assembly Interaction. NCI Thesaurus. Code C40545.

Spindle Assembly Interaction involves temporary non-covalent binding through intermolecular physical forces of attraction with the mitotic spindle that can affect spindle function and mitosis. 